\title{
RETRACTED ARTICLE: Alternative pathways of erythrocyte invasion, parasite multiplication potential and severity of the clinical episode of $P$. falciparum malaria in the Peruvian Amazon
}

\author{
Kuppusamy Chenniappan
}

Received: 17 July 2011 / Accepted: 27 September 2011 / Published online: 13 October 2011

(C) Springer-Verlag 2011

The Editors of "Parasitology Research" in agreement with the author and the publisher hereby retract this article. The article is retracted due to copyright issues that cannot be resolved.

The Editors of "Parasitology Research" in agreement with the author and the publisher hereby retract this article. The article is retracted due to copyright issues that cannot be resolved

K. Chenniappan $(\square)$

Laboratorio de Investigacion deproductos Naturales

Antiparasitarios de la Amazonia, UNAP,

Pasaje Los Paujiles, S/N-Nuveo San Lorenzo,

San Juan Bautista, Pampa chica, Iquitos 065 Peru

e-mail: lionkupps@yahoo.com 